\title{
Climate change and northern shrimp recruitment variability in the Gulf of Maine
}

\author{
R. Anne Richards ${ }^{1, *}$, Michael J. Fogarty ${ }^{1}$, David G. Mountain ${ }^{2}$, Maureen H. Taylor ${ }^{1}$ \\ ${ }^{1}$ National Oceanographic and Atmospheric Administration, Northeast Fisheries Science Center, Woods Hole, \\ Massachusetts 02543, USA \\ ${ }^{2} 2707$ N. Orchard Ave, Tucson, Arizona 85712, USA
}

\begin{abstract}
The northern shrimp Pandalus borealis is an important prey species in North Atlantic marine systems and is the target of major fisheries. It reaches its southern limit of distribution in the western Gulf of Maine (GOM), where temperature is thought to play an important role in its stock dynamics. We examined recruitment dynamics of northern shrimp P. borealis in the GOM from 1968 to 2011 and before and after 1999, when a shift to warmer temperatures occurred (Friedland \& Hare 2007). Recruitment was related to temperature during all 3 time periods and was related to the reproductive output of the population from 1968 to 2011 and 1968 to 1999 but not in the most recent period (2000 to 2011). Colder temperatures during the pelagic larval stage were associated with higher recruitment. Recruitment variability increased coincident with the 1999 temperature shift; other changes in the physical environment and lower trophic levels of the GOM have been seen as well. Whether the increase in recruitment variability signals a regime shift in the GOM is not yet clear. Increasing the reproductive potential of GOM northern shrimp through conservation measures could help compensate for increasingly unfavorable environmental conditions (warming) and increase the chances of preserving this population and its ecological role in the GOM.
\end{abstract}

KEY WORDS: Recruitment variability - Stock-recruitment - Temperature effects - Climate change $\cdot$ Ecological indicators $\cdot$ Northern shrimp $\cdot$ Regime shift $\cdot$ Gulf of Maine

\section{INTRODUCTION}

Scientists now agree that the world's climate is changing (IPCC 2007), but how, and how quickly, individual species and communities will respond to the changes is far less certain (Scheffer \& Carpenter 2003, Scheffer et al. 2009). Key questions revolve around how resilient communities are to climate-induced changes, whether there are tipping points, and if so, how and when they will occur. Regime shifts have been detected across a range of terrestrial and aquatic systems, including shallow lakes, coral reefs and deserts (Scheffer et al. 2001), but without the benefit of hindsight, it is difficult to determine whether a regime shift may be imminent or in progress.
In the Gulf of Maine (GOM, northwest Atlantic Ocean), a suite of changes in the physical environment have been observed in recent years. Freshwater inflow increased in the early 1990s with a resultant increase in stratification (Mountain 2004), and a major change in inflow current patterns occurred from 2000 to 2004 (Smith et al. in press). The nutrient regime in the deeper waters has shifted along with the change in inflow (Townsend et al. 2010). Deeper waters have cooled (Townsend et al. 2010), but the annual sea surface temperature (SST) has warmed significantly, driven primarily by warmer summer SST (Friedland \& Hare 2007). The time scale of biological response to such changes is uncertain and undoubtedly species-specific, depend- 
ing on trophic level and life history characteristics. Changes at lower trophic levels (zooplankton) have been observed (Pershing et al. 2005, EcoAP 2012), but community dynamics at higher trophic levels have remained relatively stable (Lucey \& Nye 2010).

In the GOM, the northern shrimp Pandalus borealis is at the southern limit of the species' primarily boreal distribution in the North Atlantic Ocean, and thus may be particularly sensitive to climate change. Northern shrimp are commercially and ecologically important throughout their range, including the GOM (Shumway et al. 1985). A previous study revealed top-down regulation of many northern shrimp populations; however, the GOM population did not fit this pattern (Worm \& Myers 2003), and several authors have suggested that temperature is a dominant influence here (Dow 1964, 1977, Apollonio et al. 1986, Richards et al. 1996, Worm \& Myers 2003). During a warm period spanning the 1950s (Friedland \& Hare 2007), shrimp landings in the GOM declined to zero despite continued fishing effort (Dow 1964), suggesting a population collapse during that time (Anthony \& Clark 1980, Apollonio et al. 1986). SST in the western GOM is now reaching levels seen in the 1950s (Friedland \& Hare 2007) (Fig. 1); thus, it seems possible that a transition point for this ecologically important species may be approaching.

Northern shrimp are protandrous hermaphrodites, maturing as males at age 2 in the GOM, transforming to females at age 3 and reproducing as females at ages 4 and 5, after which they die (Shumway et al. 1985, Clark et al. 2000). Females brood embryos externally and move to shallow $(<50 \mathrm{~m})$ coastal waters to release their larvae during winter. Larvae go through 6 pelagic stages before settling as benthic juveniles in late spring or early summer. Juveniles remain in coastal waters for a year or more and then

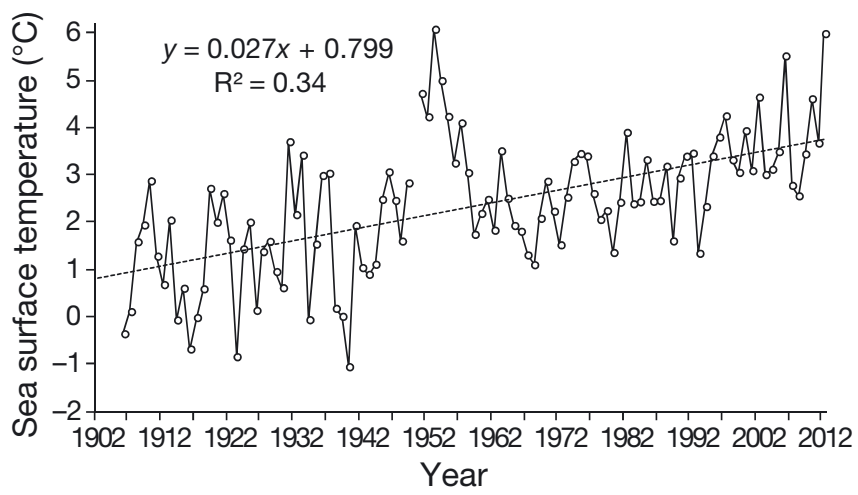

Fig. 1. Mean sea surface temperature during March from daily measurements at Boothbay Harbor, Maine, 1906 to 2011 migrate offshore to join the mature stock (Shumway et al. 1985). The fishery targets females in the winter as they come close to shore to hatch their brood.

Here, we investigate recruitment dynamics of northern shrimp Pandalus borealis in relation to reproductive output and temperature in the GOM system from 1968 to 2011. We analyze data from over $40 \mathrm{yr}$ of survey collections to identify temperature influences on shrimp recruitment and investigate whether stock-recruitment-environment relations have changed over time. We discuss our results in the context of recent changes in the GOM system and consider possible implications for the persistence of northern shrimp in the GOM.

\section{DATA AND METHODS}

\section{Biological data}

We developed a 44 yr time series (1968-2011) of recruitment and reproductive output indices for northern shrimp in the GOM (Fig. 2) by integrating data from 3 sets of fishery-independent surveys, described in detail below and summarized in Table 1. The general approach we took is as follows. For 1968 to 1983, we combined 2 surveys: one with comprehensive spatial coverage but inconsistent biological sampling of shrimp (Northeast Fisheries Science Center [NEFSC] autumn trawl survey) and one that included detailed biological sampling (length and sex) of shrimp but had more limited geographical coverage (Maine Department of Marine Resources [MDMR]). For 1984 to 2011, we used data from a single survey program designed specifically for northern shrimp (Atlantic States Marine Fisheries Commission, ASMFC, shrimp survey). Each of the resulting time series (1968-1983 and 1984-2011) was normalized by subtracting its time series mean from each observation and dividing by its standard deviation, so the 2 series could then be joined and analyzed as a continuous time series (Fig. 3A). Trends in total shrimp biomass estimated from the NEFSC and ASMFC surveys during years that both were conducted (1984 to 2008) were highly correlated $\left(\mathrm{R}^{2}=0.64\right)$.

From 1968 to 1983, the NEFSC conducted bottom trawl surveys each autumn in the western GOM (Fig. 2) according to a stratified random sampling design using standardized fishing gear ('36 Yankee' trawl with $12.5 \mathrm{~mm}$ mesh codend liner) (Grosslein 1969, Smith 2002). Approximately 40 stations were visited each year; however, detailed biological infor- 
mation on shrimp (i.e. sex, size, and life history stage) was not always collected. During the same time period (1968 to 1983), MDMR sampled 4 to 10 (average 8) fixed-location stations annually in the western GOM (Fig. 2) during late August or early September using a shrimp research trawl (32 $\mathrm{mm}$ stretch mesh codend) (Schick \& Sampson 1983). The stations were

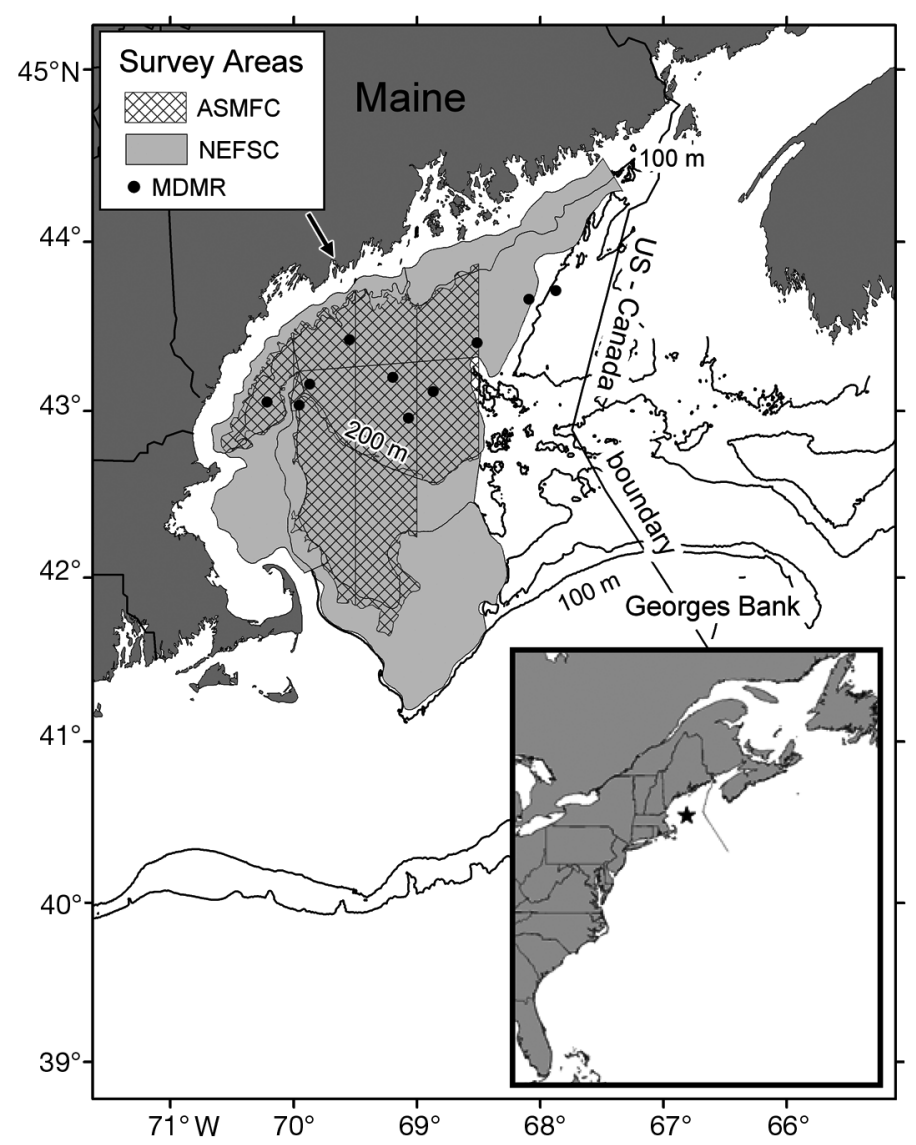

Fig. 2. Survey sampling areas in the western Gulf of Maine for NEFSC autumn trawl survey, ASMFC summer shrimp survey, and MDMR summer shrimp survey. Inset shows location of Gulf of Maine ( $\star$ ) off the US eastern coast; arrow shows location of Boothbay Harbor, Maine. See 'Data and methods' for acronyms located in areas of 'known' shrimp concentrations, and data were collected on size, sex and life history stage of Pandalus borealis. We used life history stage composition data from the MDMR survey to apportion the aggregate biomass estimates from the NEFSC survey to life history stage, i.e. spawner (Eq. 2) or recruit (Eq. 3):

$$
\begin{gathered}
I_{i j}=B_{i} P_{i j} \\
P_{i j}=\sum^{j}\left(N_{i l} W_{l}\right) / \sum^{l}\left(N_{i l} W_{l}\right) \\
P_{i j}=N_{i j} / C_{i}
\end{gathered}
$$
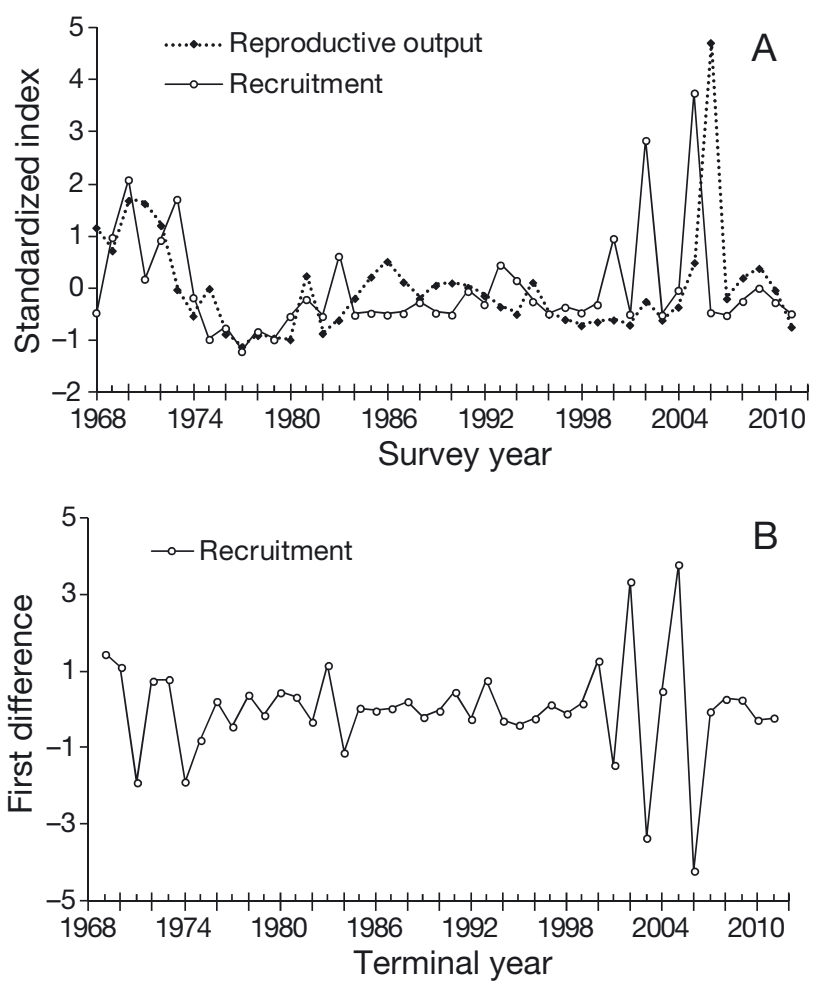

Fig. 3. (A) Normalized reproductive output and recruit abundance indices and (B) first differences of normalized recruitment series for 1968 to 2011

Table 1. Meta-data for surveys used to estimate the reproductive output and recruitment of northern shrimp. NEFSC:

\begin{tabular}{|c|c|c|c|c|c|}
\hline Survey and period & Data type & Survey design & Mesh (mm) & Timing & No. of stations \\
\hline $\begin{array}{l}\text { NEFSC } \\
1968-1983\end{array}$ & Biomass, abundance & $\begin{array}{l}\text { Stratified random, } \\
\text { bottom trawl }\end{array}$ & 12.5 & Autumn & $\sim 40$ \\
\hline $\begin{array}{l}\text { MDMR } \\
1968-1983\end{array}$ & $\begin{array}{l}\text { Biomass, abundance, } \\
\text { size, life history stage }\end{array}$ & $\begin{array}{l}\text { Non-random, } \\
\text { fixed station, shrimp trawl }\end{array}$ & 32 & Summer & $\sim 8$ \\
\hline $\begin{array}{l}\text { ASMFC } \\
1984-2011\end{array}$ & $\begin{array}{l}\text { Biomass, abundance, } \\
\text { size, life history stage }\end{array}$ & $\begin{array}{l}\text { Stratified random, } \\
\text { shrimp trawl }\end{array}$ & 32 & Summer & $\sim 40$ \\
\hline
\end{tabular}
Northeast Fisheries Science Center; MDMR: Maine Department of Marine Resources; ASMFC: Atlantic States Marine Fisheries Commission; Mesh: mesh size of codend or liner 
where $i$ is the year, $j$ is the life stage (spawner or recruit), $l$ is the dorsal carapace length, $I$ is the index (spawner biomass or recruit abundance), $B$ is the biomass index (stratified geometric mean $\mathrm{kg}$ per tow) from NEFSC autumn surveys, $P$ is the proportion of MDMR biomass index, $N$ is the mean number per tow (abundance index) from MDMR surveys, $W$ is the predicted weight at length (Haynes \& Wigley 1969), and $C$ is the biomass index (mean $\mathrm{kg}$ per tow) from MDMR surveys.

Recruits were defined as shrimp within the first fully recruited mode (assumed $1.5 \mathrm{yr}$ of age); this mode can be accurately identified by visual inspection (Terceiro \& Idoine 1990). The coefficient of variation $(\mathrm{CV})$ for the NEFSC survey biomass indices $\left(B_{i}\right)$ averaged $19 \%$; CVs for the MDMR survey indices were not available.

Our method of apportioning the biomass indices for 1968 to 1983 assumes that the relative composition of the catch in late summer shrimp surveys (August to September) is similar to that in the NEFSC autumn survey (October to November). Comparison of data for $6 \mathrm{yr}$ in which length frequencies were available from both the summer and autumn surveys supports this assumption, as there were no significant differences in relative length frequencies estimated from the 2 surveys (Komogoroff-Smirnov 2-sample tests, $\mathrm{p}>0.05$ ). Once females have spawned (September), their growth ceases until spring after the brood has hatched.

From 1968 to 1972, the NEFSC autumn survey recorded only the aggregate pandalid shrimp catch (kg per tow), which could include 3 other species in addition to northern shrimp (Wigley 1960). Therefore, northern shrimp biomass indices $\left(B_{i}\right.$ in Eq. 1 above) for 1968 to 1972 were estimated from aggregate pandalid shrimp catches using the relationship between total shrimp and northern shrimp biomass indices during the 1986 to 2000 period: $y=0.761 x-$ $0.070, r^{2}=0.81$, where $y$ is the northern shrimp biomass index, and $x$ is the total pandalid shrimp biomass index).

From 1984 to 2011, the ASMFC conducted a dedicated survey for northern shrimp, sampling $\sim 40$ stations annually in the western GOM during mid-summer (Fig. 2). Sampling was conducted according to a stratified random design using a modified commercial shrimp trawl (32 $\mathrm{mm}$ stretch mesh codend) (Clark 1989). Detailed biological data was routinely collected. For this series, we developed population fecundity indices by applying a size-fecundity relation (estimated from data in Haynes \& Wigley 1969) to the annual geometric mean number of spawners per tow of a given length (dorsal carapace length, measured to $0.5 \mathrm{~mm}$ ). The number of spawners was decremented for the annual portion of natural and fishing mortality that would have occurred before the midpoint of the hatch period (Richards 2012):

$$
\begin{gathered}
\text { PopFec }_{i}=\sum^{l} N_{i l} F c_{l} \\
N_{i l}=N_{i} \mathrm{e}^{-\left[\left(M P_{M i}\right)+\left(F_{i} P_{F i}\right)\right]} P_{l i}
\end{gathered}
$$

where $i$ is the year, $l$ is the dorsal carapace length, $\mathrm{FeC}_{l}$ is the fecundity at a given length, estimated as $\mathrm{FeC}_{l}=-0.1981^{2}+128.811-17821\left(\mathrm{r}^{2}=0.76\right), N_{\text {il }}$ is the number of spawners at length at mid-point of annual hatch period $N_{i}$ is the stratified geometric mean number of spawners per tow, $M$ is the natural mortality, assumed to be 0.25 (ASMFC NSTC 2010), $P_{M}$ is the proportion of natural mortality occurring between survey and median hatch date, $F$ is the fishing mortality (from Collie-Sissenwine model, Collie \& Sissenwine 1983) (ASMFC NSTC 2010), $P_{F}$ is the proportion of fishing mortality occurring between the survey and median hatch date, estimated from monthly effort statistics (ASMFC NSTC 'Assessment report for the Gulf of Maine northern shrimp-1994' unpubl., 2010), and $P_{l}$ is the proportion at length $l$.

Recruit abundance for 1984 to 2011 was estimated as the stratified geometric mean number per tow within the first fully recruited mode, identified by visual inspection (Terceiro \& Idoine 1990).

CVs averaged $9.5 \%$ for recruit survey indices and $3.5 \%$ for spawner survey indices $\left(N_{i}\right)$.

\section{Environmental data}

We considered ocean temperature series (Fig. 4) at lags appropriate to hypothesized biological mechanisms. The lags were relative to recruitment observed in summer at age $1.5 \mathrm{yr}$ :

(1) autumn bottom temperatures (lag 2, potential influence on incidence of egg parasitism, rates of embryonic development, hatch timing)

(2) spring bottom temperatures (lag 1, potential influence on juvenile settlement, growth and survival

(3) spring surface temperatures (lag 1, potential influence on planktonic larval development and survival

Three of the temperature series were derived from shipboard hydrographic observations made at $\sim 40$ stations in the western GOM (Fig. 2) during NEFSC bottom trawl surveys conducted during spring (1968 to 2011) and autumn (1968 to 2010). Bottom temperature measurements were made using a mechanical 

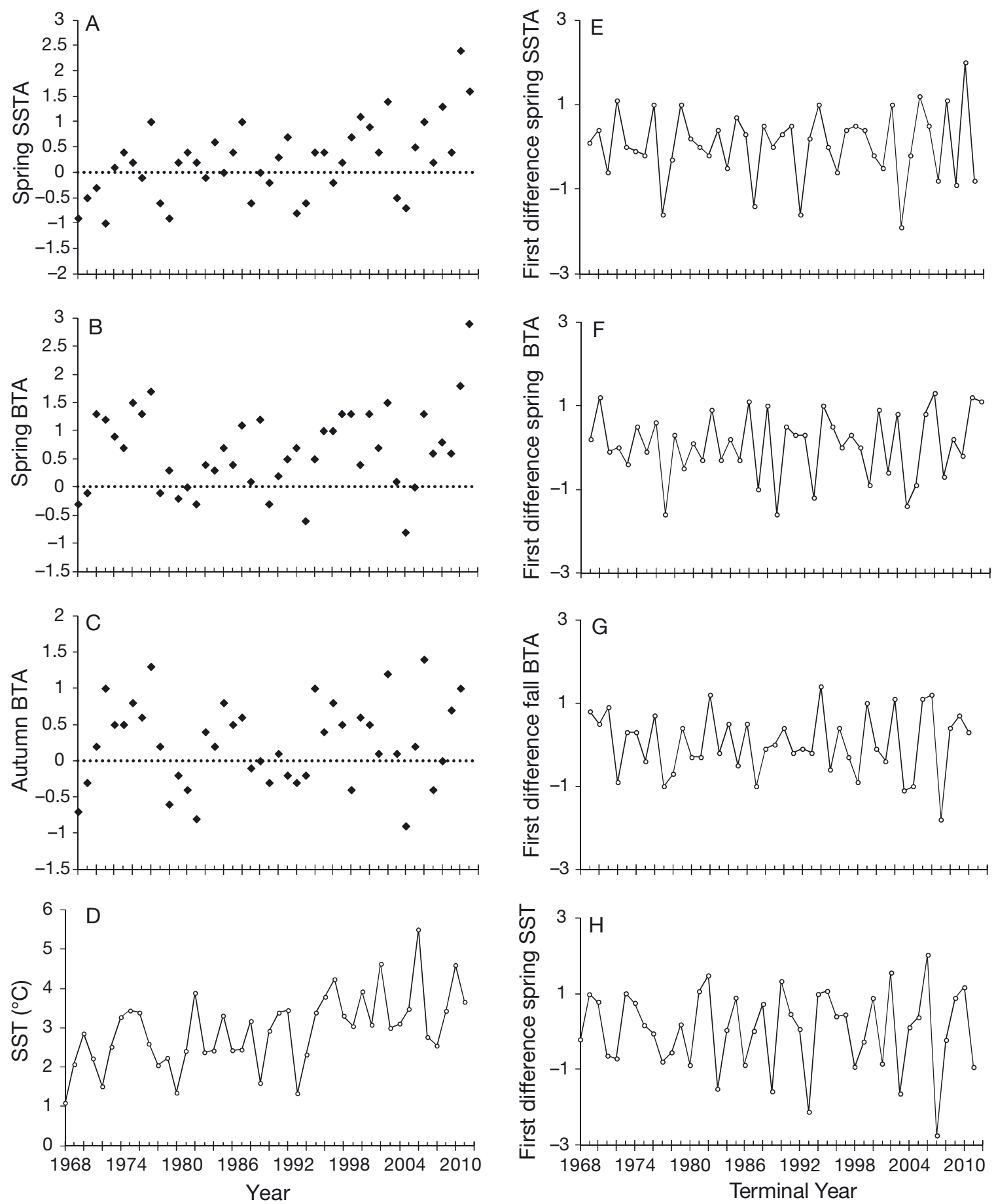

Fig. 4. (A-D) Ocean temperature data and $(\mathrm{E}-\mathrm{H})$ first differences from 1968 to 2011. (A,E) Spring surface temperature anomaly (SSTA); (B,F) spring bottom temperature anomaly (BTA); (C,G) autumn bottom temperature anomaly (1968-2010); $(\mathrm{D}, \mathrm{H})$ mean sea surface temperature (SST) during March from dock-side measurements

bathythermograph from 1968 to 1970 and an expendable bathythermograph (XBT) from 1971 to 1990, and surface temperatures were measured using a bucket and thermometer. After 1990, the surface and bottom temperatures were measured using an electronic profiling conductivity/temperature/depth (CTD) instrument. The temperatures were expressed as anomalies to compensate for variation in the timing of surveys from year to year. Anomalies were estimated relative to a set of reference annual cycles 
based on sampling conducted from 1978 to 1987 . The anomaly at each station was the difference between the observed value and the reference value for that location and date (Holzwarth \& Mountain 1990). The overall anomaly for each survey was the stratified mean of the station anomalies. The average survey date was 19 April (DoY 109) for spring and 30 October (DoY 303) for autumn.

A fourth temperature series used was SST measured daily from a dock in mid-coast Maine (Boothbay Harbor) (Fig. 2), near the center of distribution of the northern shrimp population in the GOM (www.maine.gov/dmr/rm/environmentaldata.html). The dock-based measurements were included to represent conditions in nearshore waters where juvenile settlement occurs (Shumway et al. 1985). We used average daily SST during the month of March, when the hatch period is reaching completion (Richards 2012) and the early planktonic larval stages are in the water column.

\section{Analysis}

We explored the hypothesis that shrimp recruitment dynamics have responded to a significant shift in SST in the western GOM (Friedland \& Hare 2007) by looking for evidence of a change in shrimp recruitment pattern near the identified SST change point in 1999. The recruitment time series was de-trended by taking first differences, and the differenced series was regressed on year. The residuals were tested for heteroscedasticity (Lagrange multiplier test, SAS ver. 9.1 for Linux Proc Autoreg) (SAS Institute 2008) to determine whether recruitment variability had changed significantly over time. Visual inspection of the first differences was used to identify the point at which recruitment variability changed, and the time series was divided accordingly.

We fit stock-recruitment models with environmental inputs (Cushing 1971) to each of the 3 time periods (1968-2011, 1968-1999 and 2000-2011):

$$
R=\alpha S^{\gamma} \mathrm{e}^{\sum_{i=1}^{n} \delta_{i} x_{i}}
$$

where $R$ is the recruitment index, $S$ is the lagged reproductive output index (based on spawner biomass for 1968 to 1983 and population fecundity for 1984 to 2011, standardized to normal deviates to create a continuous time series), $\alpha$ is the slope of the recruitment curve at the origin, $\gamma$ is a shape parameter, and $\delta_{i}$ are coefficients for the environmental (temperature) factors $\left(X_{i}\right)$. The temperature series were expressed as principal components (PCs) from principal components analysis (PCA) to reduce the number of variables and account for possible collinearities among the temperature series.

We fit the model using ordinary least-squares regression:

$$
\log _{\mathrm{e}} R=\log _{\mathrm{e}} \alpha+\gamma \log _{\mathrm{e}} S+\sum_{i=1}^{n} \delta_{i} X_{i}+\varepsilon
$$

where $X_{i}$ to $X_{n}$ are the PCs of temperature effects, $\varepsilon$ is a random error term, and all other terms are defined as before. We used Akaike's information criterion (AIC) scores to identify the best model for each time series. The model structure implies a lognormal error structure, which is consistent with observations of recruitment processes in many marine populations (e.g. Fogarty 1993). Residuals were examined for autocorrelation at lags of up to $4 \mathrm{yr}$.

\section{RESULTS}

The northern shrimp recruitment time series showed significant heteroscedasticity $(\mathrm{p}<0.01$, Lagrange multiplier test, SAS ver. 9.1 for Linux Proc Autoreg) (SAS Institute 2008), which was not eliminated by transformation. Visual inspection of the differenced series (Fig. 3B) revealed a sharp increase in the level of interannual variability from 1999 to 2006. Therefore, we divided the series at 1999 and analyzed from 1968 to 1999 (1969-1998 year classes [YC]), 2000 to 2011 (1999-2010 YC) and the entire period (1969-2010 YC). Recruitment variability (average interannual difference) was $41 \%$ for the 1969-1998 YC, 158\% for the 1999-2010 YC and $255 \%$ during the period of maximum variability. A period of relatively high interannual variability (124\%) also occurred from 1969 to 1975 (1968-1973 YC). In contrast to the recruitment data, tests for heteroscedasticity applied to the differenced temperature series (Fig. 4) were not significant ( $p>0.05$, Lagrange multiplier test).

The first 3 PCs in the PCA accounted for $91 \%$ of the variance in the data (Table 2); therefore, PC4 was not considered in the analysis. PC1 was weighted heavily on the 3 spring temperature variables, PC2 represented primarily autumn BTA (Table 2), and PC3 represented the contrast between spring surface temperature anomaly and dockside spring surface temperatures. Time trends in the PC scores are shown in Fig. 5. PC1 had a significant increasing trend over time $(\mathrm{p}<0.01)$; the other PCs showed no trend.

Parameter estimates for the stock-recruitment models are given in Table 3. For the full time series 
Table 2. Eigenvectors (PC) from principal components analysis of environmental variables, proportion of variance and cumulative variance explained by each eigenvector. BTA: bottom temperature anomaly, SSTA: sea surface temperature anomaly, SST: sea surface temperature from dockside measurements at Boothbay Harbor, ME

\begin{tabular}{|lrrrr|}
\hline Variable & PC 1 & PC 2 & PC 3 & PC 4 \\
\hline Fall BTA & 0.261 & 0.891 & 0.187 & 0.320 \\
Spring SSTA & 0.513 & -0.404 & 0.697 & 0.297 \\
Spring BTA & 0.597 & 0.117 & -0.034 & -0.793 \\
March SST & 0.559 & -0.171 & -0.691 & 0.425 \\
Proportion of variance & 0.537 & 0.252 & 0.123 & 0.088 \\
Cumulative variance & 0.537 & 0.789 & 0.912 & 1.000 \\
\hline
\end{tabular}

(1969-2010 YC), recruitment was positively related to reproductive output and negatively related to PC1 and PC2 ( $\mathrm{p}<0.05$, model $\mathrm{R}^{2}=0.17$ ) (Table 3, Fig. 6A-C). For the 1969-1998 YC, recruitment was positively related to reproductive output and negatively related to PC1 $\left(\mathrm{p}<0.001\right.$, model $\left.\mathrm{R}^{2}=0.48\right)$ (Fig. 6D-F). For the 1999-2010 YC, the AIC-selected model included reproductive output and PC1 $(\mathrm{p}=$ 0.06 , model $\mathrm{R}^{2}=0.35$ ) (Fig. 6G-I), but the value of the spawning parameter was nonsensical (negative). Residuals were not autocorrelated for any of the stock-recruitment models (Durbin-Watson tests, $\mathrm{p}>$ 0.05). Inclusion of the environmental term in the stock-recruitment models decreased the AIC by $7 \%$ for 1969 to $2010,17 \%$ for 1969 to 1998 and $34 \%$ for 1999 to 2010 (Table 3).

\section{DISCUSSION}

Recruitment variability of northern shrimp in the GOM increased concomitant with an identified SST transition point in the late 1990s (Friedland \& Hare 2007), and the influence of the environment on recruitment appears to have increased in recent years. Recruitment was related to both temperature and the reproductive potential of the population during the whole time period (1969-2010 YC) and during the period before the transition point (1969-1998 YC). However, the stock-recruitment relationship failed in the recent time period (1999-2010 YC), although the relationship with temperature remained strong. Spring temperatures were more influential than autumn, suggesting that the strongest impact was on larval or juvenile stages. Colder temperatures were associated with higher recruitment, but exceptionally strong YC have been produced in recent years despite an overall warming trend.
Recruitment is the product of a suite of processes acting directly and indirectly on larvae and subsequent life stages (Houde 2008). The relative importance of each process may fluctuate over time, producing recruitment variability that is often difficult to explain. However, temperature is a factor that has far-reaching effects on biological processes and reflects oceanographic and climatological conditions and thus may be a useful proxy for a variety of processes affecting recruitment (Houde 2008). In northern shrimp, inter-population comparisons and laboratory studies have demonstrated strong temperature effects on life history parameters (e.g. longevity, growth, maturation and timing of sex change) (reviewed by Shumway et al. 1985, Bergström 2000), but evidence for temperature effects on recruitment or abundance has not always clearly emerged. In a
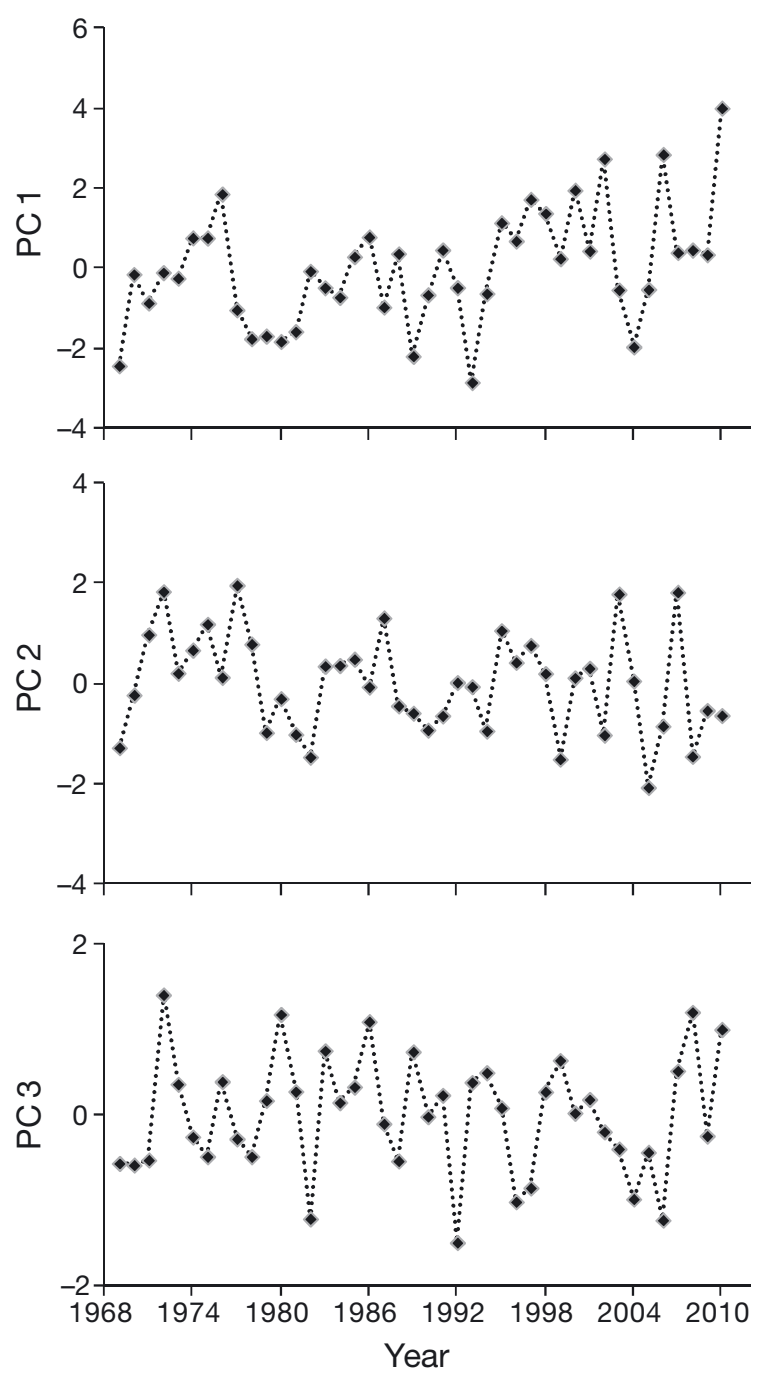

Fig. 5. Time series of principal component (PC) scores for PC1 to PC3 from 1968 to 2011 
Table 3. Parameter estimates and Akaike's information criterion (AIC) for stock-recruitment-environment models. AIC model with only reproductive output parameter included; $\mathrm{AIC}_{\mathrm{S}, \mathrm{E}}$ : full model (reproductive output and environmental effects). YC: year class; df: degrees of freedom

\begin{tabular}{|c|c|c|c|c|c|c|c|}
\hline Variable & $\mathrm{df}$ & Estimate & $\mathrm{SE}$ & $\mathrm{p}$ & Model $r^{2}$ & $\mathrm{AIC}_{\mathrm{S}}$ & $\mathrm{AIC}_{\mathrm{S}, \mathrm{E}}$ \\
\hline 1969-2010 YC model & & & & $\leq 0.05$ & 0.17 & -51.6 & -55.4 \\
\hline Intercept & 1 & 0.148 & 0.085 & 0.090 & & & \\
\hline Spawner index & 1 & 0.352 & 0.145 & 0.020 & & & \\
\hline PC 1 & 1 & -0.135 & 0.053 & 0.016 & & & \\
\hline PC 2 & 1 & -0.094 & 0.078 & 0.236 & & & \\
\hline Error & 38 & & & & & & \\
\hline 1969-1998 YC model & & & & $\leq 0.001$ & 0.48 & -48.7 & -56.9 \\
\hline Intercept & 1 & -0.057 & 0.079 & 0.476 & & & \\
\hline Spawner index & 1 & 0.601 & 0.128 & $<0.0001$ & & & \\
\hline PC 1 & 1 & -0.188 & 0.057 & 0.003 & & & \\
\hline Error & 27 & & & & & & \\
\hline 1999-2010 YC model & & & & 0.06 & 0.35 & -11.5 & -15.4 \\
\hline Intercept & 1 & 0.736 & 0.179 & 0.003 & & & \\
\hline Spawner index & 1 & -0.291 & 0.262 & 0.295 & & & \\
\hline PC 1 & 1 & -0.203 & 0.085 & 0.041 & & & \\
\hline Error & 9 & & & & & & \\
\hline
\end{tabular}

meta-analysis of 9 northern shrimp populations, Worm \& Myers (2003) found that biomass was directly influenced by predation pressure in most populations, but not by ocean temperature. Recruitment and larval survival were negatively correlated with SST in the Gulf of St. Lawrence (Ouellet et al. 2007), but in later studies, the relationship was not significant (Ouellet et al. 2011). However, positive correlations between recruitment and temperature have been seen in the Barents Sea (Aschan \& Ingvaldsen 2009) and off West Greenland (Wieland 2005), both near the species' northern limit. At the southern limit in the GOM, northern shrimp landings were negatively correlated with lagged annual SST from 1939 to 1967 (Dow 1977), and an earlier analysis of stock-recruitment-environment relations in the GOM found a negative relation between temperature and recruitment (Richards et al. 1996), as in the present study. Thus, at the extremes of the shrimp distribution, it appears that processes related to temperature play a sufficiently dominant role for temperature effects on recruitment to be consistently observed. In more central areas, the variable results likely reflect fluctuations in the particular forces dominating the recruitment process in a given year.

Predation is another driver of recruitment success (Houde 2008). In several northern shrimp populations, predation by Atlantic cod Gadus morhua is thought to influence northern shrimp population dynamics (Berenboim et al. 2000, Lilly et al. 2000, Worm \& Myers 2003, Wieland et al. 2007). However, in the meta-analysis of Worm \& Myers (2003), the
GOM was the only area that did not show a link between Atlantic cod and northern shrimp biomass proxies. In our study, including a term for predation pressure (aggregate survey biomass index of shrimp predators; Link \& Idoine 2009) in the stock-recruitment-environment model did not improve the fit of the model. Ten species, including Atlantic cod, are consistent predators of shrimp in the GOM (Link \& Idoine 2009); annual fluctuations in predation pressure could be dampened if one functional group replaces another.

The stock-recruitment models for GOM northern shrimp indicate greater resiliency and higher average size of the stock under relatively cold conditions (Fig. 6) and suggest that if temperatures continue to warm in the western GOM, the risk of stock collapse will increase, particularly under high fishing mortality. The 'warm' and 'cold' stock-recruitment curves shown (Fig. 6) represent the range of conditions already observed (upper and lower 10th percentile of annual PC scores) and do not extrapolate beyond those conditions; however, temperatures are predicted to continue to rise in the GOM (Fogarty et al. 2007). Paradoxically, the 2 largest YC on record have appeared during the past $12 \mathrm{yr}$ despite the warming trend. The exceptional 2004 YC resulted from average reproductive output coupled with cold spring temperatures, whereas the 2001 YC (second highest on record) emerged from spring temperatures near the long-term average and population fecundity $20 \%$ below the long-term median. These strong recruitments could lull fishery managers into complacency; 

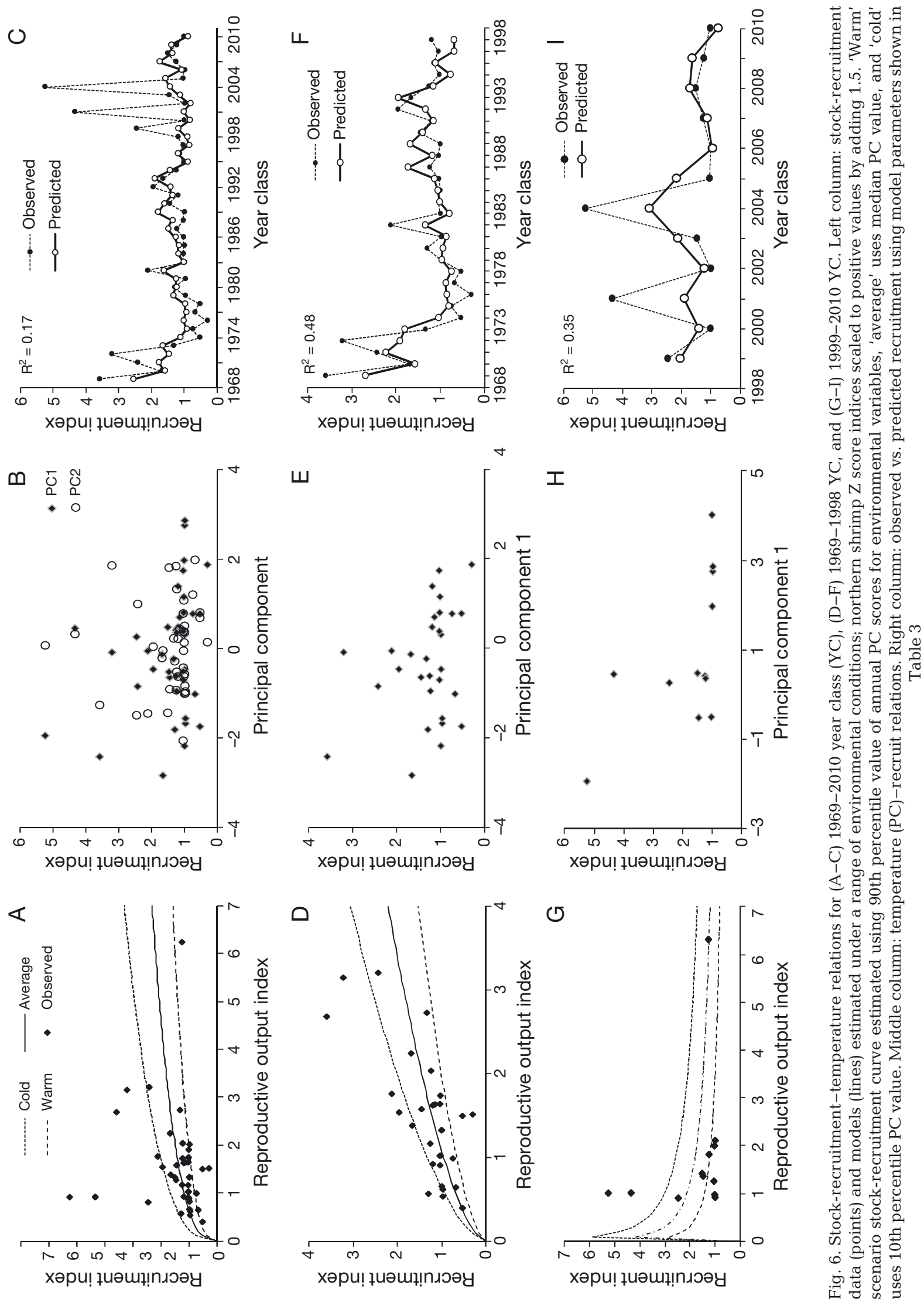

폴 
however, a prudent course would be proactive compensation for the likelihood of an increasingly unfavorable climate. The demonstration of stockrecruitment relationships is important because it implies that resource management can have a positive impact. Although fishery managers have no control over climactic variables, regulations can directly influence levels of reproductive output. One simple management option would be to shift the temporal pattern of fishing to allow more females to hatch their brood before they are captured.

Our stock-recruitment model for the recent time period (1999-2010 YC) included a nonsensical parameter estimate for reproductive output (negative). Given the shortness of the time series and the high proportion of extreme observations, this is not surprising and should not be taken to suggest that reproductive output is no longer important. Rather, we infer that environmental factors during this time period have obscured the influence of reproductive output. Removal of highly influential points (the survey years 2005, 2006 and 2008, tested individually) from the model did not alter the sign of the parameters for the 1999-2010 YC.

The mechanisms behind population-level temperature effects in the GOM are likely more complex than direct effects on growth and mortality. Stronger recruitment at colder temperatures appears intuitively correct for a population at its southern limit. However, laboratory studies with northern shrimp consistently show positive effects of warmer water on larval development and survival within the range of temperatures experienced by shrimp larvae in the GOM (Stickney \& Perkins 1977, Wienberg 1982, Nunes 1984). Previous authors have speculated that the most important effect of temperature might be on timing of the hatch relative to the timing of the plankton bloom (Stickney \& Perkins 1977, Richards et al. 1996). Close temporal matches between hatch timing and the spring phytoplankton bloom have been shown for several northern shrimp populations across the North Atlantic (Koeller et al. 2009, Ouellet et al. 2011); however, the GOM hatch was an exception to this pattern (Koeller et al. 2009). In our analysis, PC2 (primarily autumn bottom temperature) was not as important as PC1 (spring temperatures), suggesting that hatch timing and/or brood parasitism may be less critical than a variety of potential spring temperature effects. Including an alternative proxy for temperature effects on hatch timing (average daily SST during oogenesis through embryonic maturation) (Richards 2012) gave similar results. However, the role of hatch timing cannot be entirely ruled out. The duration of the hatch period has increased since the 1980s (Richards 2012), thus increasing the probability of larvae encountering a favorable window for survival. This could explain the paradox of a boreal species at its southern limit having higher recruitment under warming conditions.

A broader question is whether recent changes in recruitment variability in northern shrimp signal an impending or in-progress regime shift in the GOM. In model systems, increased variability in system behavior is observed prior to a major reorganization (Carpenter \& Brock 2006), and pandalid shrimp have been proposed as indicator species for ecosystem status because of their trophic importance and sensitivity to temperature (Anderson 2000). Interannual recruitment variability was 4 -fold greater during the recent time period (1999-2010 YC) than during the earlier period (1969-1998 YC), and 3 of the largest $\mathrm{YC}$ in the $44 \mathrm{yr}$ of record were produced after 1998 (Fig. 3). Relatively high northern shrimp recruitment variability was also seen during a period of high abundance and high fishing mortality from 1969 to 1974 (Fig. 3B); this was followed by a population collapse and closure of the fishery in 1977 (Clark et al. 2000). In the Gulf of Alaska, shrimp recruitment variability increased prior to a major ecosystem reorganization, with 2 record YC produced shortly before a severe and persistent decline in abundance of pandalid shrimps (Anderson \& Piatt 1999). However, in the GOM, recruitment indices have returned to a level only slightly lower $(7 \%)$ than during the stable period of 1978 to 1998 ; thus, it is not clear whether a change to a new state is underway. It appears possible that the relationship between shrimp recruitment and the environment has changed, because the spike in recruitment variability was not driven by an increase in inter-annual environmental variability (Fig. 4E-H).

The change in northern shrimp recruitment variability followed a transition point in annual SST (to a warmer state) identified for a broad region of the western GOM (Friedland \& Hare 2007). Additional shifts in physical and biological characteristics of the GOM environment have occurred. These shifts include freshening of surface and bottom waters due to changes in inflow sources, particularly since 1990 (Mountain 2004, Townsend et al. 2010, EcoAP 2012), and a major change in inflow patterns that occurred between 2000 and 2004 (Smith et al. in press). The inflow changes have implications for nutrient availability (Townsend et al. 2010) and for stability of the water column (stratification) (Mountain 2004) and 
thus for the composition and productivity of the phytoplankton community. Phytoplankton indices were elevated during the 1990s but declined to below average levels after 2001 (Kane 2011). Similar patterns have been seen in several zooplankton species (Pershing et al. 2005, Kane \& Prezioso 2008, EcoAP 2012), and the ratio of small-bodied to largebodied copepods has decreased steadily since 1994 (EcoAP 2012). Despite the accumulation of changes, higher trophic levels (fish and macro-invertebrates) have remained relatively stable compared to other regions of the US northeast continental shelf (Lucey $\&$ Nye 2010). The GOM has a complex food web with many predator-prey connections, which is thought to enhance its resilience (Overholtz \& Link 2009) and may buffer against the rapid ecosystem reorganization that has been seen in some other systems (Anderson \& Piatt 1999, Scheffer et al. 2001).

Understanding recruitment variability has been a long-standing challenge for marine ecologists (Houde 2008). The challenge has been intensified and its importance elevated by shifting conditions linked to climate change. Our results confirm early suggestions that temperature is an important factor controlling northern shrimp recruitment in the GOM (Dow 1964, 1966, 1977, Apollonio et al. 1986) and suggest that environmental factors may be playing a stronger role now than in the recent past. Increasing the shrimp population's reproductive potential through conservation measures could compensate for increasingly unfavorable environmental conditions and improve the chances of preserving this population and its ecological role in the GOM.

Acknowledgements. We dedicate this paper to the memory of our friend and colleague, Dr. Stephen H. Clark, who was instrumental in northern shrimp research in the Gulf of Maine for many years and whose unflagging enthusiasm, friendship and support are greatly missed. We are grateful to D. Schick, M. Hunter, M. Lazzari and others at the Maine Department of Marine Resources for providing data and insights that were important to the present study, and to the many dedicated workers of the Northeast Fisheries Science Center and member states of the Atlantic States Fisheries Commission who collected data on northern shrimp, both at sea and in the laboratory. This work was funded in part by Saltonstall-Kennedy grant NA96FD0073 to R.A.R. and M.J.F.

\section{LITERATURE CITED}

- Anderson PJ (2000) Pandalid shrimp as indicators of ecosystem regime shift. J Northwest Atl Fish Sci 27:1-10

> Anderson PJ, Piatt JF (1999) Community reorganization in the Gulf of Alaska following ocean climate regime shift. Mar Ecol Prog Ser 189:117-123
Anthony VC, Clark S (1980) A description of the northern shrimp fishery and its decline in relation to water temperature. Climate and Fisheries, Proc Workshop. University of Rhode Island, Kingston, RI

Apollonio S, Stevenson D, Dunton DK (1986) Effects of temperature on the biology of the northern shrimp, Pandalus borealis, in the Gulf of Maine. NOAA Tech Rep NMFS 42

> Aschan M, Ingvaldsen R (2009) Recruitment of shrimp (Pandalus borealis) in the Barents Sea related to spawning stock and environment. Deep-Sea Res II 56:2012-2022

ASMFC NSTC (Atlantic States Marine Fisheries Commission Northern Shrimp Technical Committee) (2010) Assessment report for the Gulf of Maine northern shrimp - 2010. Accessed 12 September 2011. www.asmfc.org

Berenboim B, Dolgov A, Korzhev V, Yaragina N (2000) The impact of cod on the dynamics of Barents Sea shrimp (Pandalus borealis) as determined by multispecies models. J Northwest Atl Fish Sci 27:69-75

$>$ Bergström B (2000) The biology of Pandalus. Adv Mar Biol 38:55-245

> Carpenter SR, Brock WA (2006) Rising variance: a leading indicator of ecological transition. Ecol Lett 9:311-318

Clark SH (1989) State-federal northern shrimp survey. In: Azarovitz TR, McGurrin J, Seagraves R (eds) Proceedings of a workshop on bottom trawl surveys. ASMFC Spec Rep 17:27-29

> Clark SH, Cadrin SX, Schick DF, Diodati PJ, Armstrong MP, McCarron D (2000) The Gulf of Maine northern shrimp (Pandalus borealis) fishery: a review of the record. J Northwest Atl Fish Sci 27:193-226

Collie JS, Sissenwine MP (1983) Estimating population size from relative abundance data measured with error. Can J Fish Aquat Sci 40:1871-1879

Cushing DH (1971) The dependence of recruitment on parent-stock in different groups of fishes. J Cons 33: 340-362

> Dow RL (1964) A comparison among selected marine species of an association between sea water temperature and relative abundance. J Cons 28:425-431

Dow RL (1966) A method of forecasting the relative abundance of northern shrimp (Pandalus borealis $\mathrm{Kr}$ ) in Maine waters. Commer Fish Rev 28:14-16

Dow RL (1977) Natural abundance fluctuations in the Maine shrimp fishery. National Fisherman, Camden, ME

EcoAP (2012) Ecosystem status report - 2011. Ecosystem Assessment Program, NOAA Northeast Fisheries Science Center Reference Document 12-07, Northeast Fisheries Science Center, Woods Hole, MA

> Fogarty MJ (1993) Recruitment in randomly varying environments. ICES J Mar Sci 50:247-260

Fogarty M, Incze L, Wahle R, Mountain D and others (2007) Potential climate change impacts on marine resources of the northeastern United States. Northeast climate impacts assessment. Marine sector report. Union of Concerned Scientists, Cambridge, MA. Accessed 12 September 2011. www.northeastclimateimpacts.org/pdf/ miti/fogarty_et_al.pdf

Friedland KD, Hare JA (2007) Long-term trends and regime shifts in sea surface temperature on the continental shelf of the northeast United States. Cont Shelf Res 27: 2313-2328

Grosslein MG (1969) Groundfish survey program of BCF at Woods Hole. Commer Fish Rev 31:22-35

> Haynes EB, Wigley RL (1969) Biology of the northern 
shrimp, Pandalus borealis, in the Gulf of Maine. Trans Am Fish Soc 98:60-76

Holzwarth T, Mountain D (1990) Surface and bottom temperature distributions from the Northeast Fisheries Center spring and autumn bottom trawl survey program, 1963-1987. NOAA Northeast Fisheries Science Center Reference Document 90-03, Northeast Fisheries Science Center, Woods Hole, MA

Houde D (2008) Emerging from Hjort's shadow. J Northwest Atl Fish Sci 41:53-70

IPCC (Intergovernmental Panel on Climate Change) (2007) Climate Change 2007: the physical science basis. In: Solomon S, Qin D, Manning M, Chen Z, Marquis M, Averyt KB, Tignor M, Miller HL (eds) Contribution of Working Group I to the Fourth Assessment Report of the Intergovernmental Panel on Climate Change. Cambridge University Press, Cambridge

Kane J (2011) Multiyear variability of phytoplankton abundance in the Gulf of Maine. ICES J Mar Sci 68:1833-1841

> Kane J, Prezioso J (2008) Distribution and multi-annual abundance trends of the copepod Temora longicornis in the US Northeast Shelf Ecosystem. J Plankton Res 30: 619-632

Koeller P, Fuentes-Yaco C, Platt T, Sathyendranath S and others (2009) Basin-scale coherence in phenology of shrimps and phytoplankton in the North Atlantic Ocean. Science 324:791-793

> Lilly G, Parsons D, Kulka D (2000) Was the increase in shrimp biomass on the Northeast Newfoundland shelf a consequence of a release in predation pressure from cod? J Northwest Atl Fish Sci 27:45-61

Link J, Idoine J (2009) Estimates of predator consumption of the northern shrimp Pandalus borealis with implications for estimates of population biomass in the Gulf of Maine. N Am J Fish Manag 29:1567-1583

> Lucey SM, Nye JA (2010) Shifting species assemblages in the northeast US continental shelf large marine ecosystem. Mar Ecol Prog Ser 415:23-33

Mountain DG (2004) Variability of the water properties in NAFO Subareas 5 and 6 during the 1990s. J Northwest Atl Fish Sci 34:101-110

Nunes P (1984) Reproductive and larval biology of northern shrimp, Pandalus borealis Krøyer, in relation to temperature. PhD dissertation, University of Alaska, Fairbanks, AK

Ouellet P, Savard L, Larouche P (2007) Spring oceanographic conditions and northern shrimp Pandalus borealis recruitment success in the north-western Gulf of St Lawrence. Mar Ecol Prog Ser 339:229-241

Ouellet P, Fuentes-Yaco C, Savard L, Platt T and others (2011) Ocean surface characteristics influence recruitment variability of populations of northern shrimp (Pandalus borealis) in the Northwest Atlantic. ICES J Mar Sci 68:737-744

Overholtz W, Link J (2009) A simulation model to explore the response of the Gulf of Maine food web to large-scale environmental and ecological changes. Ecol Modell 220: 2491-2502

Pershing AJ, Greene CH, Jossi JW, O'Brien L, Brodziak JKT, Bailey BA (2005) Interdecadal variability in the Gulf of Maine zooplankton community, with potential impacts on fish recruitment. ICES J Mar Sci 62:1511-1523

Richards RA (2012) Phenological shifts in hatch timing of

Editorial responsibility: Romuald Lipcius,

Gloucester Point, Virginia, USA northern shrimp Pandalus borealis. Mar Ecol Prog Ser 456:149-158

Richards RA, Fogarty MJ, Clark S, Schick DS, Diodati P, O'Gorman B (1996) Relative influence of reproductive capacity and temperature on recruitment of Pandalus borealis in the Gulf of Maine. ICES CM K:13

SAS Institute (2008) SAS (statistical analysis system) Ver. 9.1. SAS Institute, Cary, NC

Scheffer M, Carpenter SR (2003) Catastrophic regime shifts in ecosystems: linking theory to observation. Trends Ecol Evol 18:648-656

Scheffer M, Carpenter S, Foley JA, Folkes C, Walker B (2001) Catastrophic shifts in ecosystems. Nature 413: 591-596

Scheffer M, Bascompte J, Brock WA, Brovkin V and others (2009) Early-warning signals for critical transitions. Nature 461:53-59

Schick DF, Sampson DB (1983) Northern shrimp research in the western Gulf of Maine for 1982. Maine Department of Marine Resources Contract Completion Report, Project ASMFC 82-1, West Boothbay Harbor, ME

Shumway SE, Perkins HC, Schick DF, Stickney AP (1985) Synopsis of biological data on the pink shrimp, Pandalus borealis Krøyer, 1838. NOAA Tech Rep NMFS 30, Seattle

Smith PC, Pettigrew NR, Yeats P, Townsend DW, Han G (in press) Regime shift in the Gulf of Maine. Am Fish Soc Symp 79

Smith TD (2002) The Woods Hole bottom-trawl resource survey: development of fisheries-independent multispecies monitoring. ICES Mar Sci Symp 215:480-488

Stickney AP, Perkins HC (1977) Environmental physiology of commercial shrimp, Pandalus borealis. Project 3-202-R Completion Report, Maine Department of Marine Resources, West Boothbay Harbor, ME

Terceiro M, Idoine JS (1990) A practical assessment of the performance of Shepherd's length composition analysis (SRLCA): application to Gulf of Maine northern shrimp Pandalus borealis survey data. Fish Bull 88:761-773

Townsend DW, Rebucka ND, Thomas MA, Karp-Bossa L, Gettings RM (2010) A changing nutrient regime in the Gulf of Maine. Cont Shelf Res 30:820-832

> Wieland K (2005) Changes in recruitment, growth, and stock size of northern shrimp (Pandalus borealis) at West Greenland: temperature and density-dependent effects at released predation pressure. ICES J Mar Sci 62: 1454-1462

> Wieland K, Storr-Paulsen M, Sünksen K (2007) Response in stock size and recruitment of northern shrimp (Pandalus borealis) to changes in predator biomass and distribution in West Greenland waters. J Northwest Atl Fish Sci 39: 21-33

Wienberg R (1982) Studies on the influence of temperature, salinity, light and feeding rate on laboratory reared larvae of deep sea shrimp, Pandalus borealis Krøyer 1838. Meeresforschung 29:136-153

Wigley RL (1960) Note on the distribution of Pandalidae (Crustacea, Decapoda) in New England waters. Ecology 41:564-570

> Worm B, Myers RA (2003) Meta-analysis of cod-shrimp interactions reveals top-down control in oceanic food webs. Ecology 84:162-173

Submitted: September 15, 2011; Accepted: June 6, 2012

Proofs received from author(s): September 12, 2012 